\title{
Leituras sobre usuário e uso de informação na Ciência da Informação ${ }^{1}$
}

\section{Rodrigo Rabello}

\author{
Doutorado em Ciência da Informação pela \\ Universidade Estadual Paulista (UNESP). Pós- \\ doutorado pelo Instituto Brasileiro de Informação em \\ Ciência e Tecnologia (IBICT)
}

Considerando aspectos da literatura internacional da área de Ciência da Informação (CI) relacionados aos temas necessidade, busca, comportamento e uso da informação, objetivou-se explorar a trajetória histórica e as interpretações sobre os conceitos usuário e uso de informação, tomando, como referencial de apoio, as noções de sistema de informação e de agência dos sujeitos. Para tanto, foi delimitado como corpus 15 revisões de literatura da Annual Review of Information Science and Technology (ARIST) - que trouxeram um panorama teórico sobre os conceitos estudados. A análise dessas revisões foi instrumentalizada com as tipificações sobre uso de informação propostas por Rachel Anne Fleming-May, que permitiu situar as duas fases iniciais identificadas, que se particularizam por orbitar a noção de sistema de informação, sendo a primeira fase caracterizada por uma concepção mais estática de sistema e a segunda por uma acepção mais dinâmica. Por fim, observou-se, na literatura da ARIST, uma terceira e última fase, que passou a ser mais bem visualizada a partir da década de 2000. Naquela década, os estudos passaram a considerar, complementarmente às fases anteriores, a agência dos sujeitos a partir das noções de interação e de contexto, em ações de uso, produção e apropriação de informação e de conhecimento.

Palavras-chave: Usuário de informação; Uso de informação; Annual Review of Information Science and Technology; Ciência da Informação.

\footnotetext{
${ }^{1}$ Parte dos resultados da pesquisa de pós-doutorado intitulada "Usuário, informação e ciência e tecnologia: aspectos comunicativos e institucionais em um modelo sociotécnico emergente" finalizada em 2012 no Instituto Brasileiro de Informação em Ciência e Tecnologia (IBICT) sob a supervisão da Profa. Dra. Maria Nélida González de Gómez.
} 


\section{Readings on user and use of information in Information Science}

Considering aspects of international literature in the area of Information Science (IS) regarding need, search, behavior and use of information, this study aims to explore the historical path and interpretations of the concepts of user and use of information, under the support reference of the notions of information system and subject agency. For such, a corpus was formed with 15 literature reviews of the Annual Review of Information Science and Technology - ARIST - which brought a theoretical panorama on the concepts here studied. The analysis of these reviews was tooled with categorizations of the use of information proposed by Rachel Anne Fleming-May, making it possible to situate two initial phases identified, particularized for orbiting a notion of information system, being the first phase characterized by a more static conception of system and the second by a more dynamic meaning. Finally, a third and last phase was found in reading ARIST, which was better visualized after the year 2000. In the first decade of the 21st century, studies started considering, complementarily to previous phases, the agency of subjects from the notions of interaction and context, in actions of use, production and appropriation of information and knowledge.

Keywords: Information user; Information use; Annual Review of Information Science and Technology; Information Science.

Recebido em 27.02.2013 Aceito em18.09.2013

\section{Introdução}

O presente artigo objetiva investigar uma trajetória das acepções de usuário e uso de informação na literatura internacional da Ciência da Informação (CI), considerando como referenciais de apoio os construtos sistema de informação e agência dos sujeitos.

Com vistas a explorar tal trajetória, buscou-se fazer uma interpretação particular sobre usuário e uso de informação, instrumentalizando como corpus 15 revisões de literatura da Annual 
Review of Information Science and Technology (ARIST) ${ }^{2}$, cujos textos mapearam estudos tocantes aos temas necessidade, busca, comportamento e uso de informação entre as décadas de 1960 e 2000.

A escolha do corpus se justifica pelo fato de que essa publicação é considerada uma importante referência internacional para a área de informação, com revisões de literatura que trazem um panorama dos assuntos debatidos em CI e em tecnologia, ou seja, que trazem um estado da arte, cujos temas têm variado consideravelmente à luz da dinamicidade da disciplina (ARIST, 2012).

É interessante observar que o corpus analisado contou com textos cujos títulos foram nomeados de acordo com a tendência teórica adotada nas fontes de informação citadas e documentadas nas revisões de literatura.

Os textos de 1966 e 1967, intitulados "Necessidades e usos de informação em ciência e tecnologia" (Information needs and uses in science and techonology), datam de quando se debatia questões relativas ao uso da informação em comunidades científicas específicas ou em "escolas invisíveis" (invisible colleges).

Já os textos subsequentes, respectivamente de 1968, 1970, 1971, 1974, 1978, 1986 e 1990, foram denominados "Necessidades e usos de informação" (Information needs and uses) ou, nos anos de 1969 e 1972, intitulados de "Estudos de necessidades e usos de informação" (Information need and use studies). Ambos os títulos marcaram um momento em que se enfatizou não apenas as comunidades científicas, mas, também, os sistemas de informação e/ou os seus usuários.

Diferenciando-se deste relativo padrão identificado até 1990, nas revisões dos anos seguintes, os títulos tiveram considerável modificação, embora todos eles tivessem orbitado um mesmo tema, no caso, comportamento informacional. P. ex., o texto de 2001 foi intitulado "Estrutura conceitual em comportamento informacional" (Conceptual frameworks in information behavior); os textos de 2006 e 2009 foram denominados somente "Comportamento informacional" (Information Behavior), embora no ínterim de ambos os textos a revisão de 2007 tivesse sido denominada "O contexto na pesquisa em comportamento informacional" (Context in Information Behavior Research). Observa-se, neste último título, o enfoque dado à noção de contexto aos estudos de comportamento informacional, assunto esse que foi debatido nos demais textos daquela década.

Além dessas curiosidades a serem conferidas na trajetória interpretativa sobre usuário e uso de informação na ARIST, faz-se oportuno comentar que, logo após apresentada a série de revisões, estas serão interpretadas com o auxílio do estudo realizado por Rachel Anne Fleming-May. Em sua tese de doutorado, defendida em 2008, a autora se debruçou sobre o conceito uso na literatura da CI.

O enfoque estrito no sistema de informação, observado em FlemingMay (2008), evidenciou a primeira e a segunda fases dos estudos sobre

\footnotetext{
${ }^{2}$ Esta delimitação do corpus também foi empregada em Gasque e Costa (2010).
} 
usuário e uso da informação, fases essas direcionadas respectivamente às dimensões objetiva e/ou subjetiva de informação, algo que sofreu redirecionamento em uma terceira fase, identificada nas revisões da ARIST da década de 2000.

Observou-se que, a partir dessa década, os estudos passaram a considerar, complementarmente, a dimensão social da informação, bem como as noções de interação e de contexto junto à ação dos sujeitos que fazem uso, produzem e se apropriam de informação e de conhecimento.

Espera-se que as revisões e as interpretações expostas no presente texto possam fornecer ao leitor um panorama dos estudos sobre usuário e uso de informação no cenário internacional da CI nas últimas décadas.

\section{Uma trajetória interpretativa sobre usuário e uso de informação}

Analisando a produção entre 1963 e 1965, a revisão de Herbert Menzel admite avanços e a possibilidade de progresso teórico por intermédio da construção de instrumentos quantitativos, relevantes à aplicação de amostragem e à sistematização, categorização e tabulação de dados.

A ideia de comportamento, considerada naquela investigação, foi relacionada à experiência dos cientistas e tecnólogos durante o processo comunicativo em contato com diferentes canais. O comportamento foi analisado, primeiro, sob os enfoques da preferência, da demanda e dos estudos experimentais, para, depois, se estender aos estudos de uso e aos estudos de disseminação (MENZEL, 1966, p. 45-65).

Em particular, os resultados obtidos com os estudos de uso destacavam aspectos ineficientes no processo de comunicação, buscando diagnosticar, com antecedência, carências e possíveis erros. Além disso, traziam relatos de casos de sucesso e de cientistas que destacavam a satisfação quanto às experiências recentes de acesso e uso de informação, em análises de dados mediante estudos de incidentes críticos.

Os estudos sobre disseminação da informação consistiam na análise do processo de comunicação sob o ponto de vista do autor-cientista, como um disseminador da informação. Para tanto, foram realizadas pesquisas quantitativas com diferentes tipos de convenções psicológicas investigadas com a aplicação de questionário.

Os autores Saul Herner e Mary Herner foram os próximos a contribuir com a ARIST, escrevendo sua revisão de literatura no ano seguinte à publicação do texto de Menzel e tomando como parâmetro os estudos dos anos de 1965 e 1966.

Os teóricos trouxeram, assim como na revisão anterior, a situação dos problemas encontrados nos estudos de usuários. Ampliaram, para tanto, o leque de pontos críticos, destacando as poucas técnicas de pesquisa utilizadas para a difícil incumbência de estudar a diversidade de tipos de usuários. Além disso, a variabilidade e a ambiguidade da linguagem técnica empregada, somada à carência de inovação, 
fracassariam em fundamentar os resultados obtidos, pois os erros não foram apreendidos, visto que não havia projetos experimentais vigorosos.

Os autores propuseram um modelo de processo de comunicação da informação para o campo por meio de componentes que se interrelacionariam de diferentes formas. P. ex., escritos originais, apresentação de ideias (métodos ou atividades), resultados de pesquisas, etc., são transmitidos mediante eventos, comunicações informais, publicações diversas (canais ou meios), com vistas a informar o receptor da mensagem. Nesse processo, segundo Herner e Herner (1967, p. 3), a mensagem é convertida em informação.

Foram identificadas, a partir do modelo criado, duas classes de estudo de usuários: a) estudo básico (particular, específico) - investiga a forma de criar o conhecimento ou o entendimento quanto à fonte de informação, ou seja, como o usuário atribuiu valor a um dado durante o processo avaliativo; e b) estudo aplicado (geral) - relacionado às operações de pesquisa, isto é, às tomadas de decisão a partir do estudo das formas pelas quais os dados poderão ser utilizados e da identificação de aspectos qualitativos quanto à transmissão das informações.

Após discorrerem sobre as técnicas de estudo empregadas - diários e registros administrados pelos usuários, entrevistas, observações, questionários, estudos indiretos e técnicas de estudo combinados - todas direcionadas a resultados passíveis de mensuração, os autores concluíram que, embora tenham sido aplicadas muitas vezes de forma precária e experimental, tais técnicas geraram informações úteis e verificáveis no que tange à obtenção de padrões de uso e de requisitos necessários ao sistema (HERNER; HERNER, 1967, p. 30).

Em 1968, a revisão de William Paisley deu continuidade à série de estudos, analisando as produções dos anos 1966 e 1967. O autor defendeu o aprofundamento das relações interdisciplinares entre tais estudos e trouxe um panorama de problemas metodológicos no âmbito dos estudos de necessidade e uso.

À luz da complexidade de um sistema de informação, os estudos observados desconsideraram o conjunto das fontes de informação e o contexto pelo qual as informações são disponibilizadas - consequências do uso da informação - além de não considerar aspectos contextuais específicos, como a experiência, a motivação, a orientação profissional etc. dos usuários, sob a influência dos sistemas social, político e econômico.

Partindo do pressuposto da existência de pobreza conceitual e da necessidade de busca por variáveis para o controle de fontes de informação, o autor sugeriu o caminho do estudo do comportamento do processamento da informação para a identificação de variáveis complexas importantes para a delimitação conceitual e teórica dos estudos sobre necessidade e uso de informação.

Nessa direção, Paisley (1968, p. 3) propôs uma estrutura conceitual com vistas a apresentar variáveis que deveriam ser acomodadas em qualquer teoria abrangente. Para tanto, partiu do pressuposto de 0 cientista estar, precisamente, dentro de sistemas. Esse caminho foi 
utilizado para a tentativa de compreensão das necessidades e usos da informação, contextualizando o cientista/tecnólogo nos sistemas pelos quais realiza seu trabalho.

Para compreender o sistema e para melhorar a transferência de informação seria necessário, segundo o autor, integrar os sistemas computacionais de armazenamento e recuperação de informação aos sistemas social, político e econômico e considerar os aspectos culturais para pensar a interação do cientista com o sistema. O sistema, nesse contexto, foi pensado a partir de variáveis (sistemas e subsistemas) que apresentam valor categórico e envolvem o trabalho do cientista, estando esse indivíduo: a) dentro de uma cultura, b) dentro de um sistema político, c) dentro de um grupo de sócios (sociedade particular), d) dentro de um grupo de referência (especializado), e) dentro de uma escola invisível, f) dentro de uma organização formal, g) dentro de um grupo de trabalho/pesquisa, h) dentro de um sistema legal/econômico, i) dentro de um sistema formal de informação (bibliotecas, centros de informação, etc.) e, por fim, j) dentro de sua própria cabeça (estrutura cognitiva).

O autor responsável pela continuidade da revisão de literatura foi Thomas Allen, que analisou, em 1969, textos referentes ao ano de 1968. Para tanto, utilizou como referência a estrutura conceitual de Paisley (1968), ou seja, pensou o usuário em uma série de sistemas concêntricos e sob o espectro da ciência do comportamento.

Em sua estrutura de análise, Allen (1969, p. 4-18) reduziu o sistema concêntrico de Paisley (1968) de dez elementos para seis. Considerou o cientista e o tecnólogo em seu comportamento particular como processador de informação que pode se relacionar com um grupo de trabalho/pesquisa, com uma organização (instituição), com uma sociedade profissional, com uma escola invisível ou com um sistema de informação formal.

O cientista e o tecnólogo, na condição de processadores de informação, atuam em comunicações informais ou formais, estando, esta última, necessariamente relacionada a uma instituição que interage com algum tipo de fluxo de informação. A concepção desse tipo de usuário está relacionada com o processo cognitivo abordado por Paisley (1968), no que tange à escolha do canal de informação, bem como ao processo de uso, em sua variação de acordo com a necessidade específica de busca.

O contexto do grupo de trabalho/pesquisa pode abranger dois tipos: a) grupo de pessoas que trabalham num mesmo projeto ou b) grupo de pessoas que compartilham informações num mesmo interesse funcional e/ou disciplinar.

Além disso, o indivíduo poderá atuar em uma organização formal ou informal. No caso da organização formal, a ação será valorizada em relação à realização do processo de comunicação de forma padronizada e que considere o fluxo de informação. Já no caso da atuação em uma organização informal (surgida espontaneamente), a ação está relacionada às necessidades pessoais, sem obedecer, necessariamente, padrões formalizados, embora possa receber a influência de uma estrutura de comunicação ou de uma organização formal. 
O indivíduo em uma sociedade profissional tende a manter diálogos informais frutíferos ocorridos, p. ex., durante ou após a participação em um evento. Tais diálogos poderão se converter na formalização de parcerias entre pesquisadores, algo que revela a importância do contato do autor com outros cientistas para debater o texto apresentado e/ou publicado.

A participação do cientista e do tecnólogo em uma escola invisível pode ser apreendida mediante o relacionamento de fatores tais como a comunicação informal, a colaboração contínua, a orientação ou a influência na defesa de teses e a influência na seleção de problemas, de teorias e de métodos e/ou técnicas. Os membros poderiam ser identificados por meio da escolha de citações, conceitos, referências, etc., em comunicação formal ou informal.

Ao fazer uma análise sobre os estudos em necessidade e uso de informação, Allen (1969, p. 24) identificou, até aquele momento, pouca unidade do campo de estudo de usuários, isto é, observou a dificuldade para o desenvolvimento de uma estrutura teórica mais sólida. Isso poderia ser atribuído à dispersão de pesquisadores interessados no tema em diferentes disciplinas ou aos poucos estudos em Comunicação e em CI.

Os estudos da década seguinte foram inaugurados com a revisão de literatura de Ben-Ami Lipetz, que tomou como parâmetro a preocupação de Paisley (1968), direcionada aos estudos elaborados com vistas a identificar o perfil dos usuários.

Os estudos de necessidade e uso foram concebidos por Lipetz (1970, p. 3), a partir da atividade criativa de descrição do uso, definição de conceitos e da teorização causal, assim como dos resultados quantitativos relativos ao uso de informações e dos fatores relacionados. Tal concepção tem, como pano de fundo, iniciativas direcionadas à explicação dos fenômenos observados, bem como à previsão e à manipulação das condições essenciais de uso.

Nesse estudo, Lipetz (1970, p. 4-17) seguiu o caminho de Allen (1969) e adaptou as categorias de Paisley (1968) para pensar a necessidade e o uso da informação de cientistas e tecnólogos. Os usuários foram concebidos como processadores de informação para o uso seletivo de canais de informação. O ambiente no qual atuam - as organizações foi considerado, bem como as especificidades das sociedades profissionais e a formação de escolas invisíveis. De modo específico, o sistema formal de informação foi tematizado a partir das necessidades e demandas por informação, estudo de leitores, circulação e uso de coleções, distribuição de periódicos e de citações ${ }^{3}$.

\footnotetext{
${ }^{3}$ Conforme a interpretação de Lietz (1970, p. 4-17), o cientista e o tecnólogo, como processadores de informação, foram analisados primeiramente em sua ação de uso seletivo de canais avaliáveis, enfatizando a abordagem dos canais informais de comunicação. No caso da organização como ambiente de pesquisa, destacaram-se os estudos da comunicação no meio organizacional, considerando, dentre outras coisas, a relação entre inovação tecnológica com a exequibilidade técnica e a demanda, a disseminação, o tratamento, o acesso e o aproveitamento da informação a partir do nível de escolaridade/formação. Para o estudo da atuação dos usuários em sociedades profissionais e em escolas invisíveis, foi observado o processo de comunicação antes, durante e
} 
No plano metodológico, foram classificados os métodos empregados nos estudos de necessidade e uso de informação. No caso dos estudos diretos, observou-se a incidência da aplicação de questionário, entrevista, método de diário, observação e análise de dados. No âmbito dos estudos indiretos, foram empregadas estatísticas de circulação e de citação, por meio de amostragens. Segundo Lipetz (1970, p. 18), as ferramentas mais utilizadas, na época estudada, eram, em primeiro lugar, a entrevista, seguida pelo uso do questionário e da observação.

No plano teórico, foram observados por Lipetz (1970, p. 20) estudos com o foco na atividade de busca por informação, considerando o relacionamento de dois sistemas de comunicação já apontados por Menzel (1966), o formal e o informal. O autor considera relevante criar modelos teóricos e metodológicos para interpretar os resultados investigados, mesmo à luz das inúmeras variáveis que podem ocorrer durante o processo de investigação. Tais modelos seriam consequências dos resultados dos testes das hipóteses intermediados, mormente, pela sua aferição estatística e probabilística.

A revisão de literatura seguinte foi sistematizada, em 1971, por Diana Crane, que dividiu o texto em três frentes: a) discussão sobre necessidade e uso de informação no âmbito das ciências básicas, b) discussão da literatura a partir do contexto das tecnologias, c) relação entre os aspectos internacionais e as necessidades e usos da informação para pensar o campo disciplinar.

Os estudos em necessidade e uso de informação, segundo Crane (1971, p. 6), são produzidos e reproduzidos em: a) estudos da literatura científica: abrangência, razão do crescimento e padrões de citação, b) estudos de como os cientistas usam a literatura, c) estudos da organização social entre os cientistas - padrão de comunicação, sistema de compensação e ambiente organizacional.

A discussão sobre necessidade e uso de informação perpassou pela figuração da organização social e pelo desenvolvimento intelectual de uma área de pesquisa. Ademais, transcorreu pela conexão entre áreas mediante a difusão da informação e por intermédio da inovação num sistema de comunicação formal numa área ou por meio do processo de busca de informação sob as variáveis de tal sistema (CRANE, 1971, p. 627). Essa concepção considerou os seguintes elementos: organização social da ciência, desenvolvimento intelectual, inter-relacionamento entre

\footnotetext{
depois de encontros científicos, bem como a importância da relação informal entre usuários para a disseminação da informação. Quanto às necessidades e demandas, destacou-se a existência de diferentes graus de exigência do acervo e do profissional mediador da informação, bem como os distintos níveis de confiança quanto às habilidades do profissional responsável pela busca da informação e quanto à capacidade de o sistema atender suas necessidades. Os estudos de leitores profissionais/docentes foram direcionados à comodidade de leitura, à satisfação do veículo e às necessidades do conteúdo disponibilizado, importância da linha editorial, qualidade das publicações etc. Quanto à circulação e uso da coleção, o enfoque foi dado à utilização de métodos quantitativos como subsídio para a gestão de bibliotecas, com a aplicação de modelos de probabilidade de modo a predizer atividades futuras. A distribuição de periódicos e de citações foi tematizada por meio da aplicação de procedimentos, como a aplicação da lei de Bradford, a análise do uso de estatísticas de citação, a análise de frequência de autores em periódicos etc.
} 
áreas, difusão da informação, busca de informação, inovação num sistema de comunicação formal e dimensão tecnológica.

A organização social de uma área de pesquisa pode ser pensada em dois tipos: a) grupo solidário - composto de professores e alunos e geralmente aberto a receber novos membros que queiram e/ou possam construir e compartilhar conhecimento, b) escola invisível ou rede - liga os grupos solidários de modo a fluir a informação na área de investigação.

Segundo a autora, o desenvolvimento intelectual pode ser beneficiado pela comunicação científica. Quanto menor o número de publicações ou citações em uma área, menor o compartilhamento de conhecimento e, portanto, maior a dificuldade de seu desenvolvimento.

O inter-relacionamento entre áreas pode ser observado por meio da análise de citações. Ademais, destacam-se os estudos sociométricos e os estudos da comunicação informal de pesquisas.

A difusão da informação em uma área de pesquisa pode ocorrer mediante um sistema de comunicação formal, como encontros profissionais e de pesquisa e os textos apresentados e publicados nos documentos dos eventos ou em periódicos.

A busca de informação num sistema de comunicação formal (em periódicos, serviços de resumo e indexação, livros, etc.) pode apresentar problemas, tais como os de linguagem de especialidade e de tratamento de conteúdo em sistemas de informação, refletidos na dificuldade de recuperação da informação.

A inovação em um sistema de comunicação formal, segundo a autora, pode ser beneficiada com a criação de categorias com o intuito de enfrentar problemas no processo comunicativo.

A dimensão tecnológica dos estudos de necessidade e uso de informação pode ser relacionada à própria busca de organização da área no inter-relacionamento entre os líderes de comunicação do campo, em sua prática de pesquisa, e os "guardiões" ou editores (gatekeepers) das organizações industriais e das fontes de informação ${ }^{4}$.

$\mathrm{O}$ estudo que deu prosseguimento às revisões de literatura da ARIST foi desenvolvido, em 1972, por Nan Lin e por William Garvey, com vistas a analisar a literatura em necessidades e uso de informação publicada no ano anterior. De modo específico, essa revisão objetivou trazer a discussão que envolve os pesquisadores (usuários) e os "arquitetos" de sistema de informação (science policy-makers) sobre a importância dos estudos para o design dos sistemas de informação.

De acordo com Lin e Garvey (1972, p. 5-6), os estudos de necessidade e uso de informação contribuem para a discussão sobre a estrutura básica (tronco) da ciência e tecnologia e a sua relação com a sociedade, sobretudo no cenário em que há o crescimento da dimensão aplicada daquela estrutura, encarregada de produzir e disseminar o

\footnotetext{
${ }^{4}$ Conforme observa Crane (1971, p. 28-29), os aspectos que influem os estudos de necessidade e uso na relação dos agentes com as tecnologias, são: a) posição organizacional e o trabalho formal de seleção de uma fonte de informação, b) comportamento de busca da informação, c) preferência do tipo de fonte, d) competência técnica/conhecimento para a realização da busca de informação.
} 
conhecimento. Nesse contexto, os estudos de necessidade e uso de informação são importantes para a construção de sistemas em conformidade com a necessidade e o anseio social.

O até então esforço teórico, segundo Lin e Garvey (1972, p. 7), para a significação de uma estrutura conceitual nos estudos de necessidade e uso de informação e das questões sobre as redes de comunicação formal e informal, necessitariam perpassar pelas fases do sistema de informação científica. O processo de busca, nesse sistema, dependeria e se relacionaria com o trabalho prévio de organização e gerenciamento da informação.

Para tanto, além do conceito informação, deveria ser considerado o padrão comportamental singular do usuário com a estrutura socioeconômica da ciência e tecnologia vinculada a cada fase. Os fatores diferenciais para a geração das necessidades de informação e dos seus tipos foi o caminho inicial observado na literatura por Lin e Garvey (1972, p. 9-12) para situar os cientistas e os tecnólogos nos estudos de necessidade e uso de informação.

As variáveis para a geração da necessidade de informação do usuário de um sistema de informação científica podem transcorrer segundo o tipo de trabalho (pesquisa, docência, etc.), a facilidade de avaliação e o tipo de fonte de informação.

Já os tipos de necessidade podem ser observados em relação ao(s): a) critérios de controle prévio das fontes de informação de interesse, contidas em um sistema de informação, sendo categorizados pela substância ou natureza do material e expressa no gênero da documentação (livros, periódicos, etc.) ou no tipo do instrumento (resumos, bibliografias etc.); b) canais formais de comunicação (encontros e reuniões científicas etc.); c) suporte oferecido para a criação e manutenção de produtos e serviços de informação no sistema, com vistas à satisfação da demanda por informação.

Os padrões de transferência da informação foi outro caminho observado por Lin e Garvey (1972, p. 12-17). Tais padrões foram abordados em diferentes níveis, como o macroscópico, a comunicação em organizações, a comunicação em eventos e os padrões de transferência informal de informação.

Ademais, observou-se a diferenciação do uso da informação científica e tecnológica entre usuários experientes (como cientistas e tecnologistas) e inexperientes. A particularidade de tais contextos foi exposta por Lin e Garvey (1972, p. 19-25) em duas linhas: uma relacionada ao uso de publicações primárias e de canais informais e a

\footnotetext{
5 O nível "macroscópico" considera dados agregados a partir de tendências e estruturas da ciência e tecnologia para conceituar uma estrutura de comunicação informal ou em escolas invisíveis. O nível da comunicação em organizações considera dados agregados da relativa permanência organizacional e institucional para mapear as redes informais de comunicação. O nível da comunicação em eventos considera dados agregados a partir da transferência de informação realizada formal e informalmente por cientistas e tecnólogos em eventos. Já o nível padrões de transferência informal da informação - dados agregados a partir de estudos interdisciplinares sobre o padrão de comunicação informal e sobre redes numa escola invisível (LIN; GARVEY, 1972, p.12-17).
} 
outra relacionada ao uso de informação científica e tecnológica por usuários inexperientes.

A revisão seguinte ficou a cargo de John Martyn que, em 1974, trouxe um panorama sobre os estudos de usuários desenvolvidos desde a década de 1960, destacando enfoques e tendências.

A premissa da necessidade de se estabelecer um quadro categórico de usuário, haja vista a carência de estudos dessa ordem, sobretudo na década de 1960, foi pautada por Martyn (1974, p. 3) que defendeu a realização de estudos de usuários considerando um universo maior de participantes, bem como a necessidade de se estudar sistemas particulares.

Conforme observado, o intuito dos estudos de usuários consistia, em um primeiro plano, em personalizar o sistema de informação, buscando resultados para auxiliar no design do sistema. Contudo, não raras vezes, o pesquisador se deparou com a complexidade para identificar hábitos e necessidades do público estudado. De acordo com Martyn (1974, p. 3), muitos estudos não forneceram informações que poderiam ser usadas para fins de tomadas de decisões ou para o desenho de sistemas.

Embora reconhecesse o estágio de infância da disciplina estudo de usuários, a revisão de literatura de Martyn (1974, p. 5) buscou trazer elementos teóricos que justificassem essa necessidade exteriorizada nos estudos que estavam sendo desenvolvidos. O autor, para tanto, propôs direcionar a investigação do efeito da informação para subsidiar o desenvolvimento de estudos focados na modificação/aperfeiçoamento de um sistema específico, orientado por um problema particular de uma área, ou auxiliar os estudos empenhados em descrever as características gerais dos usuários das áreas ciências sociais e humanidades, algo que, até aquele momento, segundo Martyn, era escasso.

As principais tendências identificadas por Martyn (1974, p. 6-17) têm como base os estudos orientados pelo sistema (e seus componentes) e as pesquisas orientadas pelo contexto.

Os estudos orientados pelo sistema podem relacionar os serviços de informação, com o auxílio tecnológico, com o tratamento técnico da informação e com aspectos subjetivos dos usuários em relação àqueles serviços. No caso dos estudos orientados por componentes, destacam-se aqueles relacionados a canais e meios de comunicação e às classes (variedades) de informação. Já as pesquisas orientadas pelo contexto, geralmente são desenvolvidas em estudos especulativos e exploratórios, preocupando-se, p. ex., com a ecologia da informação ou com os estudos de usuários que podem envolver canais, emissores, receptores, escolha de dados, componentes (infraestrutura, fontes formais e informais) e o comportamento dos fluxos de informação, em sua relação com o uso.

Os estudos de usuários, para Martyn, têm o desafio de reconhecer a necessidade dos usuários para adequar o sistema da melhor forma ao que é desejável, sem desconsiderar as possibilidades e os limites para mudanças e aperfeiçoamentos. Pressupõe-se que, se os usuários não são conhecidos, logo, o sistema não poderá ser projetado de maneira a satisfazer as necessidades de quem usa. Porém, há de se considerar os 
seguintes aspectos: a) dificuldade de se conhecer as necessidades de informação que são complexas e variadas, b) incapacidade de atender, em todas as circunstâncias, as necessidades de todos os usuários.

Outra dificuldade refere-se aos sistemas em que o profissional de informação projeta-se em um primeiro plano, além e aquém da importância do usuário. Nessa concepção, Martyn (1974, p. 20) explica que o profissional delineia o sistema de informação a partir do seu conhecimento prévio e daquilo que concebe como útil para o usuário, mesmo sem consultá-lo ou sem conhecer a natureza dos usuários potenciais do sistema.

Em uma direção diferente à citada, Martyn (1974, p. 21) propõe aperfeiçoar o sistema a partir da interação entre usuário-sistema, com base em uma primeira tarefa que considera a consecução do estudo de interação e, em uma segunda, que leva em consideração o âmbito educacional, com vistas a ensinar o usuário e a divulgar o sistema. Nesse sentido, o estudo de usuário não estaria estritamente direcionado ao design e às operações de um sistema.

A última revisão de literatura da década de 1970 ficou a cargo de Susan Crawford que, em 1978, fez o levantamento dos trabalhos publicados entre 1975 e 1977. Ademais, essa revisão buscou abordar o conceito de necessidade e uso de informação, somando-se a alguns aspectos metodológicos sobre estudos de usuários e os diferentes usos, ou as distintas finalidades atribuídas à informação, pelo usuário.

Crawford observou estudos empíricos sobre comportamento, sob perspectivas interdisciplinares e considerando variáveis, como o relacionamento sociopolítico e interpessoal. Segundo a autora, métodos de natureza quantitativa, como o de incidentes críticos, constituem importantes ferramentas para, p. ex., a delimitação de amostragem de recebimento de informações.

Dentre os artigos analisados por Crawford (1978, p. 63-64), a grande maioria foi de natureza aplicada e contaram com a combinação de métodos qualitativos e quantitativos para a consulta de uma audiência massiva. Se por um lado a combinação de métodos apresentou como ponto positivo a obtenção de importantes resultados, mediante instrumentos de coleta bem projetados e selecionados, com emprego, em alguns casos, de técnicas estatísticas, por outro, observou-se que, mesmo com a mescla de métodos, as observações baseadas em populações limitadas e em metodologias divergentes restringiram as habilidades de generalização e de desenvolvimento de teorias.

Segundo Crawford (1978, p. 71), o cientista, como usuário de informação, tem em sua prática de pesquisa características importantes para a compreensão de seu comportamento. Tal prática pode fornecer informações, p. ex., durante o processo de distinção de aspectos da decisão política (no processo de formulação do problema) ou no percurso da própria aplicação, mediante procedimentos metódicos.

Além da figura do cientista e do tecnólogo, na revisão de literatura de Crawford (1978), reconheceu-se, pela primeira vez, nas revisões da 
ARIST, a necessidade de ampliação do escopo dos estudos de usuários abrangendo outras disciplinas e novos públicos. Observou-se, ainda, a incipiência dos estudos com enfoques voltados às questões teóricometodológicas, embora tenha identificado avanços conceituais e metodológicos. Ademais, identificou a contribuição de conceitos das ciências sociais para os estudos de usuários quando combinados com técnicas quantitativas, bem como com o reconhecimento da importância da distinção entre aspectos cognitivos e sociais da informação.

Outro aspecto relevante referiu-se ao reconhecimento de que o aumento do número de estudos de usuário poderia contribuir para unir aspectos conceituais e analíticos da necessidade e uso da informação. Esse aumento e a consideração de universos mais amplos contribuiriam, segundo Crawford (1978), para a construção de teorias gerais e para a aproximação de categorias com vistas a contemplar o maior número de casos de interesse em estudos de usuários.

A única revisão de literatura da ARIST, sobre necessidade e uso de informação, na década seguinte, foi elaborada no ano de 1986 por Brenda Dervin e por Michael Nilan, em um texto que passou a ser referencial. Nesse trabalho, foram analisados mais de 300 artigos publicados entre 1978 e 1986, com o foco nas pesquisas que ilustram o desenvolvimento das investigações sobre estudos de necessidade e uso de informação.

A identificação da pouca reflexão teórica e da obscuridade dos estudos sobre necessidade e uso de informação foi tomada em contraponto à premissa de que a construção da CI perpassa tanto pelo desenvolvimento de pesquisas empíricas, como pelo desenvolvimento teórico. Essa premissa motivou Dervin e Nilan (1986) a proporem, em sua revisão de literatura, um arcabouço conceitual de modo a situar as pesquisas teóricas e aplicadas analisadas com vistas a orientar a proposição de possíveis outras investigações.

O texto de Dervin e Nilan (1986, p. 6-8) trouxe a primeira interpretação sobre a hipótese da mudança de um modelo teórico antigo para outro que considerasse novos serviços e sistemas flexíveis a mudanças, sobretudo para o aproveitamento de recursos tecnológicos. Tal modificação de perspectiva teórica refletiu no entendimento de necessidade e uso então direcionado para a melhoria no sistema.

Segundo os autores, no modelo antigo ou paradigma tradicional preponderava os estudos de natureza quantitativa. Em tais estudos o sistema de informação tinha centralidade, bem como o gestor responsável pelo seu desenho, arquitetura e manutenção. Tal centralidade focava não apenas o serviço per se, mas, também, fetichizava a tecnologia, os dados, o conteúdo informacional e o documento como instâncias autolegitimadoras diante da sua função no sistema.

No modelo antigo, o que mais importava nos estudos de usuários era a satisfação de uso em relação ao sistema. Ao realizar a avaliação da qualidade da informação, o foco perseguido pelo profissional de informação era a necessidade do sistema, mais do que a necessidade dos usuários. Os estudos de comportamento, nesse sentido, enfocavam a 
interação usuário-sistema; já os estudos de avaliação de necessidade tinham como foco o próprio arquiteto do sistema.

No novo modelo ou paradigma alternativo, por sua vez, o estudo preponderante era o de natureza qualitativa. A centralidade do estudo voltava-se não mais ao sistema e nem ao profissional de informação, mas ao usuário. Nesse caso, o usuário seria o principal ator para se pensar demandas e necessidade de uso, bem como para se pensar a qualidade do serviço de informação.

Os esforços teóricos questionadores do "paradigma tradicional", além de introduzir novos métodos e variáveis, também deslocaram a prática de pesquisa em $\mathrm{CI}^{6}$.

No que tange aos aspectos objetivos e subjetivos da informação, no paradigma tradicional a informação objetiva é apreendida com um significado constante, em correspondência absoluta com a realidade. Já no "paradigma alternativo", o enfoque é atribuído à informação subjetiva, com significado circunstancial, e não visa representar a complexidade da realidade.

Quanto à assimilação de informação, no paradigma tradicional, o usuário tem uma atitude passiva frente à informação objetiva, a partir do pressuposto de que toda informação no sistema é, por definição, objeto usável, ou seja, constitui-se como objeto de interesse simplesmente por pertencer ao sistema. No "paradigma alternativo", por sua vez, o usuário tem uma postura ativa em seu comportamento de uso que está ancorada na interpretação, na atribuição de sentido.

No que se refere à obtenção de resultados para a delimitação do perfil do usuário, no paradigma tradicional ocorre a predição transsituacional, que consiste em um modelo que tem como horizonte a universalidade, abarcando a predição de resultados do perfil de todos os usuários em relação a todas as situações identificadas. Já no "paradigma alternativo", segundo Dervin e Nilan (1986, p. 14), há a defesa de estudos de usuários "situacionais", amparada por abordagens conceituais específicas.

Com relação ao modo de interação entre usuário e sistema, o paradigma tradicional é orientado por uma concepção "atomística", em que há a desconsideração do contexto que interfere na relação do usuário com o sistema, ou seja, considera-se uma relação causa-efeito. No paradigma alternativo, há a interação de uma concepção de "experiência holística" que também considera o contexto na relação usuário-sistema e suas variáveis. Nesse caso, o comportamento informacional é analisado fora do contexto do sistema.

No tocante à discussão sobre a individualidade do usuário, enquanto o "paradigma tradicional" enfoca o comportamento informacional externo, no "paradigma alternativo" tem-se como foco a cognição do usuário.

\footnotetext{
${ }^{6}$ Os autores Belkin, Brookes, Dervin, Hammarberg, Jarvelin e Repo, Levitan, Markey, Mick et al., Neill e Rudd, e Wilson estavam conduzindo, segundo Dervin e Nilan (1986), esforços teóricos em direção a um paradigma alternativo.
} 
O paradigma tradicional orienta-se pelo estudo do comportamento a partir da predição de resultados, ou seja, busca subsídio mediante a definição de "padrões" universais de individualidade, diante da dificuldade de aceitar a imprevisibilidade e a complexidade do indivíduo. Já o paradigma alternativo tem dedicado seus estudos ao comportamento do usuário, reconhecendo a imprevisibilidade de resultados a partir das variáveis cognitivas, tomando a adição dos valores individuais como objeto de estudo.

A única revisão de literatura da ARIST sobre necessidade e uso de informação, na década de 1990, foi produzida por Elizabeth Hewins. Nessa investigação, a autora tomou como recorte temporal os textos produzidos entre 1986 e 1989 e objetivou não enfocar estudos de caso específicos.

$\mathrm{Na}$ estrutura conceitual proposta, Hewins (1990, p. 146) reconhece o avanço de Dervin e Nilan (1986), quando abordam sobre a mudança de paradigma tradicional para o alternativo, mas ressalta que um novo paradigma estaria naquele momento em processo de emersão. Esse quadro diferencial surgiria da tensão entre as abordagens tradicionais (estudos empíricos) em relação com as emergentes, que visa apresentar uma estrutura racional, somada a uma base sistemática de métodos e definições.

Ao considerar a influência das mudanças tecnológicas ocorridas desde 1986 para os estudos de necessidade e uso de informação, Hewins pensou em uma estrutura em que há o entrelaçamento entre um modelo que se orienta considerando a articulação entre o design de mecanismos, a construção do sistema de recuperação da informação e a adaptação às necessidades do usuário e outro que se preocupa mais com as características dos usuários do que com a mensuração do desempenho do sistema.

Ao resgatar outras revisões de literatura da ARIST - como as de Menzel (1966), de Herner e Herner (1967), de Paisley (1968) e de Allen (1969) - os resultados levaram Hewins (1990, p. 148) a concluir que o problema na construção teórica perpassou por todos aqueles capítulos.

Um problema identificado foi o da dispersão dos estudos de necessidade e uso de informação em diferentes disciplinas, além de diagnósticos descentralizados, com ênfase em qualquer tipo de fonte de informação ou no abastecimento de informação pelo sistema. Uma solução sugerida por Hewins (1990, p. 152) é a da necessidade de ampliação do escopo de disciplinas, transcendendo as disciplinas sob o espectro das ciências sociais, como as pesquisas no campo do marketing e do negócio ou no âmbito da administração pública.

No âmbito da Biblioteconomia e CI, a autora observou que o foco dos estudos situa-se sobre o uso e o comportamento do usuário, em abordagens interdisciplinares que examinam sistemas e a necessidade de informação. Sob essa perspectiva, o usuário é tomado como o foco dos estudos, diferentemente dos estudos anteriores que tinham o profissional de informação (mediador) como agente principal. Segundo Hewins (1990, p. 154), no novo paradigma o uso apresenta posição central na pesquisa, 
passando a deslocar o profissional intermediador da informação para uma posição menos privilegiada.

Segundo Hewins (1990, p. 156), são dois os entendimentos possíveis a partir das abordagens destacadas por Dervin e Nilan: 1) busca pela integração das diferenças individuais dos usuários ao desenho de sistemas para interfaces; e 2) determinação dos pontos em comum no que tange à cognição dos usuários. Tais abordagens, conforme explica Hewins (1990, p. 158), são operacionalizadas com base em uma espécie de meta-disciplina que integra todas as possibilidades de estruturas conceituais na $\mathrm{CI}$, considerando relações multidisciplinares com a Psicologia Cognitiva, Inteligência Artificial, Ciência da Computação, Filosofia, Matemática, Linguística Semântica, entre outras disciplinas.

Em síntese, o paradigma centrado nos usuários, que congrega aspectos teóricos sobre inteligência humana e comportamental para o desenho de sistemas, tem buscado subsídio na Psicologia Cognitiva, como é o caso da teoria do estado anômalo do conhecimento (Belkin), dos estudos sobre influência motivacional acerca da necessidade e busca de informação (Neuberg e Fiske) e sobre a questão-negociação (Taylor; Dervin e Dewdney).

A abordagem antiga, de ênfase sociológica, que tomava como objeto cientistas e grupo de cientistas (sociólogos, químicos, físicos etc.) que utilizavam a informação, teve o seu quadro conceitual ampliado. Em uma nova abordagem, os estudos de uso de informação reconhecem que as necessidades ocorrem tanto cognitiva como socialmente (HEWINS, 1990, p. 164). Nessa nova abordagem, os esforços estariam voltados para a construção de interfaces a partir de características comuns (categorias), em uma perspectiva interdisciplinar, na qual a abordagem comportamental aparece como eixo direcionador.

A revisão de literatura da $A R I S T$, que inicia as discussões na década seguinte sobre uso e usuário de informação, foi desenvolvida por Karen Pettigrew, Raya Fidel e Harry Bruce. Nesse estudo, os autores buscaram dar continuidade à reflexão sobre o conceito de comportamento informacional, iniciada por Dervin e Nilan (1986), quando alocado como dispositivo para se pensar a mudança da abordagem antiga à abordagem alternativa, e resgatado por Hewins (1990), que defendeu que o conceito tem sido empregado na literatura e tem contribuído para o desenho e o gerenciamento de sistemas de informação. O texto de Pettigrew, Fidel e Bruce (2001, p. 44) trouxe uma revisão do desenvolvimento de estruturas conceituais para o estudo do comportamento informacional.

Os autores iniciaram a discussão sobre se o termo comportamento informacional (information behavior) seria adequado para nomear 0 campo de estudo. Enquanto autores como Wilson defendem o uso do termo, outros, como Jesse, entendem a expressão como sinônimo de necessidade, busca e uso de informação. Outros, ainda, associam negativamente o termo ao paradigma comportamentalista na Psicologia e consideram o termo impreciso, pois a informação não se comporta, já que quem o faz são as pessoas, no caso, os usuários. Entretanto, Pettigrew, Fidel e Bruce (2001, p. 44) observam, concordando com Wilson (2000), 
que o termo teve ampla aceitação em títulos de revistas científicas, artigos e em eventos da área.

O lugar onde estão situadas as discussões teóricas sobre o comportamento informacional tem sido buscado mediante análises bibliométricas e análise de citações, no âmbito das Ciências Sociais e, especificamente, da CI. O processo de maturação dos estudos em comportamento informacional, de acordo com Pettigrew, Fidel e Bruce (2001, p. 46-67), tem se desenvolvido em três eixos, notadamente em abordagens cognitiva, social e multifacetada.

Diante do caráter agregador que a abordagem cognitiva tem apresentado para a investigação sobre a necessidade e uso de informação, os estudos do comportamento da informação têm assumido a posição de catalisadores teóricos da perspectiva cognitiva. Sob esse prisma cognitivo, segundo Pettigrew, Fidel e Bruce (2001, p. 46), foram delineados construtos para a compreensão do comportamento informacional, fundamentalmente, no âmbito individual.

Essa abordagem, de modo geral, não considera o contexto envolvente ao comportamento informacional e tem como cerne a concepção cognitiva de "estruturas de conhecimento", constituindo-se como o modelo mental do indivíduo sobre o mundo, bem como o condicionante ao comportamento informacional, quando o indivíduo atua percebendo, interpretando, modificando ou transferindo informação. A abordagem cognitiva interessa-se, portanto, pela visão de mundo do indivíduo e seu reflexo na necessidade, busca, disseminação e uso da informação ${ }^{7}$.

Na década de 1990, foi registrado um crescimento dos estudos do comportamento da informação numa abordagem social, aproximando o foco das discussões ao âmbito das Ciências Sociais. As ênfases das pesquisas permearam o interesse pelos significados e valores em relação aos aspectos sociais, socioculturais e sociolinguísticos, tomando, como pano de fundo, a ideia da existência de estruturas sociais. De acordo com Pettigrew, Fidel e Bruce (2001, p. 54), as abordagens sociais foram desenvolvidas para enfrentar fenômenos do comportamento informacional que estão além do reino de estruturas cognitivas.

Os enfoques dos estudos de aspectos sociais, no âmbito do comportamento informacional, tem se direcionado à compreensão do impacto das relações interpessoais, à apreensão da dinâmica dos fluxos de informação e ao entendimento da forma como está ocorrendo o compartilhamento de informações no processo comunicativo. O interesse do estudo do comportamento informacional, de acordo com Pettigrew, Fidel e Bruce (2001, p.56), reside nos aspectos envolventes à legitimação e à justificação de valores, considerando, para tanto, a esfera social.

\footnotetext{
${ }^{7}$ Dentre os trabalhos citados por Pettigrew, Fidel e Bruce (2001, p. 50), merece destaque o desenvolvido por Kuhlthau. A importância do modelo de Kuhlthau para a abordagem cognitiva/comportamental reside na ênfase à investigação de um episódio individual, de necessidade e busca de informação, que independe do contexto. À luz dos pressupostos da perspectiva cognitiva, outros autores foram citados por Pettigrew, Fidel e Bruce (2001), como Yerbury e Parker, Cole, Vakkari, Wilson, Erdelez, entre outros.
} 
Por fim, os autores apresentaram a dimensão multifacetada dos estudos do comportamento da informação que se figuram diante da impossibilidade de uma única perspectiva explicar o fenômeno. Como exemplo, apresentou o trabalho de Allen que identificou quatro modelos dos estudos do comportamento da informação: cognitivo, social, sóciocognitivo e organizacional, embora tais modelos necessitassem, na época, da existência de um modelo integrador.

Esse contexto interdisciplinar demonstra, segundo os autores, a existência de um corpo teórico emergente em um núcleo centrado no usuário que vem relacionando comportamento de informação ao processo comunicativo em diferentes perspectivas (cognitiva, social, cultural, organizacional). Portanto, esse corpo teórico parte de uma perspectiva integradora para a construção e incorporação de novos elementos e aprimoramento dos elementos existentes.

O estudo seguinte foi elaborado por Donald Case, em 2006, abrangendo as pesquisas dos anos de 2001 a 2004, a partir do conceito de comportamento informacional. O conceito é entendido pelo autor como a interação de sujeitos com uma ordem de fontes em potencial que pode direcionar o interesse e a necessidade de informação.

De acordo com o levantamento realizado pelo autor em outra ocasião, os usuários categorizados por ocupação correspondem à incidência mais comum, seguido daqueles categorizados por função. Os categorizados social e demograficamente são os menos retratados na literatura; já as discussões sobre teorias, modelos e métodos indicam como e o porquê do estudo do comportamento da informação.

Fazendo uma análise das teorias, modelos e métodos, Case (2006) destacou a importância da produção de Dervin, Wilson, Kuhlthal, Chatman, Hj申rland e Savolainen, em sua influência para a realização de estudos empíricos em comportamento informacional. $O$ autor considerou que as metateorias mais influentes no campo são transferência de informação, construtivismo e construcionismo.

À luz das múltiplas abordagens existentes, Case (2006, p.310) converge com Bates no que tange à necessidade da busca pela compreensão mútua entre pesquisadores e seus enfoques, ao invés do enfrentamento de posições epistemológicas, embora pondere, concordando com Hjprland, que muitos teóricos da CI tendem a evitar questões filosóficas fundamentais subjacentes à pesquisa.

Dentre as propostas teóricas para pesquisa de comportamento informacional, segundo Case (2006, p. 311), há aquelas com ênfase em aspectos objetivos e/ou subjetivos, tal como as teorias postuladas por Ford (2004) e Hjprland (2004), bem como aquelas, levadas a cabo por Johnson (2003) e Cool (2001), que destacam o contexto e a situação como aspectos relevantes.

Nesse último caso, o contexto está sendo empregado de modo progressivamente mais complexo, ou seja, equivalente à situação na qual o processo está imerso. Duas orientações foram apresentadas: 1) positivista, cujos fatores moderam os relacionamentos - nessa orientação, 
aspectos contingentes a situações têm efeitos específicos; 2) póspositivista, cujo agente individual é inseparável do contexto, sendo avaliado sob estruturas de significados.

No plano metodológico, Case (2006, p. 312-313) destacou o modelo conceitual de pesquisa em comportamento da informação, empregado por Järvelin e Wilson (2003), a análise de avaliação social (social judgment analysis), utilizado por Sreft-Mabry (2003), e a tipologia adotada por Wilson (2002). Esta última tem na observação a raiz para a coleta de dados, utilizando, em particular, a observação etnográfica e o emprego de questionários e entrevistas.

O comportamento informacional, em suas abordagens individual e social, apresenta maior ênfase considerando a relação contexto e influência social, além do enfoque no conteúdo cognitivo do buscador e no tempo gasto pelo informante. Segundo Case (2006), em tais abordagens há a preocupação de se fazer uma descrição global profunda.

O autor enfatizou, ainda, a influência de Brenda Dervin nas pesquisas das últimas décadas; algo que tem motivado o crescimento da pesquisa em necessidade e busca de informação, considerando a abordagem sense-making, que tem como pano de fundo o construtivismo e o construcionismo. De acordo com Case (2006, p. 314), o questionamento de Dervin às formas estáticas de "necessidade e uso" de informação foi importante para a posterior concepção de uma natureza dinâmica do comportamento informacional.

A revisão de literatura seguinte foi realizada em 2007 por Christina Courtright, tendo como foco as publicações dos dez anos anteriores, considerando a concepção holística de Dervin e Nilan (1986) e desconsiderando o contexto limitado exclusivamente ao ambiente eletrônico ou cingido à recuperação da informação.

Diante do reconhecimento de que contexto, embora ainda pouco discutido, constitui um quadro referencial para o estudo do comportamento informacional e que esse quadro não está claro do ponto de vista dos atores e de sua operacionalização prática, a revisão de Courtright (2007) objetivou examinar e comparar os modelos existentes de contexto no campo e analisar como o conceito tem sido abordado na pesquisa empírica nos estudos de necessidade, busca e uso de informação sob um paradigma centrado no usuário (user-centered paradigm). Para tanto, buscou cotejar o modelo antigo, que privilegia a interação com o sistema, com aquele dos últimos 20 anos que tem privilegiado o estudo dos processos particulares de busca e uso da informação dos usuários, independentemente da fonte ou do sistema.

O contexto (context) é considerado pelos pesquisadores do campo como um quadro referencial, encontrando equivalência nos termos cenário (setting), ambiente/meio (environment), mundo da informação (information world), mundo da vida (life-world), campo/área da informação (information ground). A expressão, por vezes, encontra equivalência ou contraposição ao termo situação. No caso em que ocorre a diferenciação, é relevante observar que enquanto o contexto refere-se a estruturas de sentido, situações dizem respeito a ambientes dinâmicos 
onde se desdobram o processo interpretativo. Tal processo decorre da busca dos usuários por recursos de informação ao passo em que constroem a situação de interação dentro de um contexto. O contexto é constituído, segundo Courtright (2007, p. 276), por elementos conceituais que têm influências mais duradouras e previsíveis nas práticas de informação. Com efeito, a amplitude da concepção de contexto em tais práticas tende a considerar a noção de situação como uma parte potencial daquele conceito.

Os enfoques centrados no sistema, em cujo comportamento é avaliado com base a dados supostamente imutáveis, ou seja, demográficos, geográficos, estruturais; ou no usuário, em uma perspectiva fundamentalmente cognitiva, com ênfase na necessidade, busca e uso da informação, por vezes relegam a um segundo plano os fatores externos ao ator. Tais exterioridades, quando abordadas, tendem a ser enfatizadas apenas na medida em que são construídas pelo indivíduo. Diante disso e considerando o caráter amorfo e evasivo da noção de contexto na literatura, Courtright (2007, p. 276-277) reconhece, concordando com Thomas e Nyce (2001), a necessidade de se construir um conceito de contexto para pensar o comportamento da informação e o paradigma centrado no usuário em um modelo que transcenda as influências teóricas cognitivas ao se considerar o usuário como o ator da ação.

Nesse modelo emergente, o ator informacional insere-se em um contexto na condição de organizador e definidor do próprio contexto, atuando não somente em atividades diárias, mas como protagonista em organizações e instituições, em redes interpessoais, exposição a canais de comunicação compartilhados e reciprocamente reconhecidos, convergindo para a formação de um campo de informação regular.

Quando além do âmbito institucional, o contexto pode ser de difícil delimitação conceitual. Outros estudos vêm abordando o contexto fora do ambiente institucional, como é o caso daqueles que tomam a teoria social como referencial. Essas investigações vêm demonstrando as limitações atinentes à abordagem da organização. Em concordância com Pettigrew (1999, p. 811), segundo Courtright (2007, p. 279), o contexto não implica somente a um agrupamento físico, mas também a certas configurações sociais, incluindo atores e normas.

Parte dos estudos que se diferenciam das investigações sobre práticas informacionais no contexto organizacional tem dedicado à pesquisa da vida cotidiana. Entretanto, há a possibilidade de se estabelecer relações de similitude entre os enfoques organizacional e vida cotidiana, sobretudo no tocante às regras e recursos e às normas organizacionais. No caso, a vida cotidiana também se insere no âmbito das práticas informacionais, em um conjunto de locais institucionais (bibliotecas, escolas, órgãos públicos etc.) que apresentam como variáveis aspectos de acessibilidade, de confiabilidade institucional e da relevância da informação para suprir determinada necessidade (COURTRIGHT, 2007, p. 282). 
As tecnologias de informação fazem parte do contexto por estarem envolvidas nas práticas de informação e na expectativa dos atores concernente ao tipo de informação que se busca. Em relação às tecnologias, o contexto pode assumir o sentido de container, de construção de significado, de construção social e de ente relacional (COURTRIGHT, 2007, p. 284).

No sentido de container, os elementos existem efetiva e objetivamente em torno dos atores, podendo ser mensuráveis por meio da observação. As influências das atividades de informação são assumidas a partir do contexto que envolve o ator em cuja interação se torna objeto de estudo. Nesse caso, o contexto é alocado como pano de fundo para a busca das características principais do comportamento informacional. Tal enfoque insere-se no escopo dos estudos positivistas ou objetivistas, nos quais o contexto é figurado como um conjunto de entidades estáveis e delineáveis que podem ser concebidas independentemente das atividades de seus participantes. Se o contexto é um repositório ou pano de fundo para as práticas de informação, então a pesquisa não poderá explicar a variabilidade dos atores em condições de familiaridade ou igualdade de condições. Assim, nem todas as ações poderão ser previsíveis, como pretende prever o modelo positivista (COURTRIGHT, 2007, p. 286-287).

A noção de contexto no âmbito da construção de significado se diferencia ao contexto de container, na medida em que parte da análise do ponto de vista do ator, ou da pessoa-em-contexto (person-in-context), ou seja, das influências e das variáveis percebidas e construídas pelo usuário que busca informação em necessidades no plano das dimensões psicológicas, afetivas e cognitivas.

Pode-se questionar a adequação desse modelo por, a rigor, não considerar a complexidade, a variabilidade das interações mútuas, redes sociais, tecnologias da informação, práticas organizacionais, etc., isto é, por predominar as dificuldades e restrições das ações de informação a partir de variáveis decorrentes de algum fator pessoal, interpessoal, ambiental, situacional e da fonte envolvida.

No sentido da construção social dos indivíduos, o contexto é pensado a partir de seres sociais que constroem a informação por meio da interação social e não somente por processos cognitivos internos. A crítica ao modelo dos estudos da pessoa-em-contexto reside no argumento de que os atores sociais constroem a informação mediante interações sociais. Segundo Courtright (2007, p. 289), a crítica ao modelo da pessoa-emcontexto está fundamentada na concepção de que os atores são seres sociais que constroem a informação por meio da interação social e não apenas cognitivamente.

Já no contexto relacional (embeddedness), Courtright (2007, p. 289) sintetiza em sua revisão autores que levam à concepção de que a ideia de ator social e contexto estão vinculados entre si. Nesse caso, as variáveis externas influenciam a ação estabelecendo uma intersecção entre o indivíduo e o pesquisador. 
A mudança de enfoque centrado no sistema (system-centered) para o centrado no usuário (user-centered) trouxe a diferenciação de tomar como ponto de partida o ator, ou seja, valorizar as ações de informação que são predicáveis de acordo com variáveis do ambiente, sem regressar a um sistema centrado.

As implicações metodológicas referem-se aos riscos de se apresentar um cenário simples para as atividades de informação e de propor uma mera descrição do contexto sem fazer maiores explanações, desconsiderando variáveis contextuais que influenciam a ação do ator. Para minimizar tais riscos, há a necessidade de se explicar as regras subjacentes ao contexto para compreender as atividades de informação.

A última revisão de literatura sobre necessidade, busca e uso de informação, até então publicada na ARIST, ficou a cargo de Karen Fisher e de Heidi Julien, em 2009. As autoras buscaram enfocar tais ações no âmbito do comportamento informacional destacando as produções sobre o assunto nos anos de 2004, 2005 e início de 2008, direcionadas à necessidade, busca, gestão, disseminação e uso da informação, considerando os vários papéis sociais que compõe a vida cotidiana (FISHER; JULIEN, 2009, p. 317).

Em relação à realização de pesquisas sobre o tema, os autores comentam que os métodos que recentemente vem sendo aplicados provêm das Ciências Sociais, considerando método como sinônimo de técnica ou instrumentos de pesquisa (entrevistas, questionários, metaanálise etc.).

A ideia de contexto específico foi abordada como uma variável importante na realização de estudos de caso, destacando investigações preocupadas com a melhora da disseminação/disponibilidade da informação em sistemas de informação. Já em relação a estudos e construções teóricos de âmbito mais genérico, os autores reconhecem criticamente que há uma lacuna na área.

Reconhecem, por sua vez, a existência de avanço no estudo do contexto no campo nos últimos anos, sobretudo com a atenção dada às variáveis sociais a partir da década de 1990, momento em que foram estudados fenômenos específicos (situações e contextos) para pensar o comportamento informacional. O contexto, como um conceito complexo e dinâmico e que pode expressar fontes e relações de poder, poderá fazer referência ao que é disposto/fornecido no processo de busca da informação ou à situação ou tópico geral de interesse, de desenvolvimento pessoal ou, ainda, à motivação geral da busca de informação.

No âmbito dos fatores humanos que envolvem a pesquisa em comportamento informacional foram enfocadas investigações sobre o contexto acadêmico que envolve cientistas e estudantes, além dos contextos atinentes a grupos ocupacionais, a vida cotidiana das pessoas e a informação e saúde.

No estudo comportamental relativo a grupos ocupacionais, foi dado destaque à relação entre lugares de trabalho e as mudanças tecnológicas, bem como à tomada de decisão no processo de resolver problemas tecnológicos, além de fazeres governamentais e cívicos (no setor público). 
Conforme explicam Fisher e Julien (2009, p. 326), os estudos que consideraram a vida cotidiana foram realizados com vistas a destacar a necessidade de uma compreensão detalhada dessas especificidades a fim de melhorar as oportunidades de serviços de informação, bem como contribuir para os esforços de construção teórica no campo. O enfoque de pesquisa abordado considerou: a) jovens - adolescentes em meio urbano (sexualidade, finanças e mundo social), estudantes do ensino fundamental e médio, crianças usando serviço de referência digital, comportamento de busca de crianças na web (experiência, orientação e habilidade de navegação); b) mulheres - donas de casa, mulheres em meio rural, violência doméstica contra mulheres; c) idosos, imigrantes; e d) interação e transferência/compartilhamento de informação na vida diária.

Os estudos sobre o contexto no âmbito da saúde foram concebidos como um subcampo da busca da informação da vida cotidiana. Foram postos em relevo, p. ex., a necessidade e busca de informação de pacientes com câncer, mulheres com câncer, bibliotecas que oferecem serviços a usuários com algum problema de saúde ou para pessoas com curiosidade sobre assuntos relacionados ao tema da saúde.

Outro eixo temático abordado, além dos fatores humanos que envolvem a pesquisa em comportamento informacional, foi o das fontes de informação, abrangendo comunicação interpessoal, redes sociais e Web e biblioteca (FISHER; JULIEN, 2009, p. 332).

\section{Usuário e uso de informação no âmbito do sistema de informação}

O percurso observado nas revisões de literatura da ARIST será analisado, em primeiro lugar, considerando as contribuições teóricas de Rachel Anne Fleming-May, em seu estudo sobre o conceito uso na literatura da Biblioteconomia e $\mathrm{CI}^{8}$.

A análise evidenciará aquelas que seriam as duas fases iniciais presentes nas revisões de literatura da ARIST até aqui analisadas, tocantes, especificamente, ao:

a)sistema de informação, numa concepção mais estática; e ao

b)usuário no sistema de informação, numa acepção de sistema aparentemente mais dinâmica.

\footnotetext{
${ }^{8}$ A autora refere-se à expressão ciência da informação (empregada no presente estudo de forma ampla) utilizando outra recorrente expressão: library and information science (LIS). Em sua opinião, embora LIS comumente tenham sido consideradas uma mesma disciplina, library (Biblioteconomia) interessa-se pela natureza da informação, mas no contexto da biblioteca, ou seja, interessa-se por questões teóricas e metodológicas direcionadas à aquisição da informação, seu processamento técnico e intelectual, além da disponibilização de acesso a serviços e recursos de informação numa biblioteca. Já a information science (Ciência da Informação) converge com o desenvolvimento disciplinar da documentation (documentação), trazendo questões sobre a natureza da informação e sua organização, busca, acesso e uso por pessoas isoladas ou em grupo num contexto que pode transcender ao da biblioteca, mediante o instrumental de tecnologias de informação (FLEMING-MAY, 2008, p. 53).
} 
Isso porque se entende que em tais fases encontram-se pressupostos teóricos já consolidados e que auxiliam conceitualmente os estudos sobre usuário e uso no campo.

Essas fases historicamente têm levado em conta, como fio condutor, a noção de sistema e de instituição intermediadora de informação, responsável por gerir e disseminar, para recuperação e uso, produtos e serviços de informação.

Nessa direção, a pesquisa de Fleming-May (2008) reúne aspectos teóricos que tradicionalmente vêm orientando pesquisas na $\mathrm{CI}$, trazendo pressupostos cujo locus do sistema reside na noção de biblioteca, tendo como participante, ou agente principal, o usuário do sistema.

A diversidade de significados de uso levou a autora a levantar questões sobre se o ato de usar se daria quando se utiliza o espaço físico da biblioteca, ou no momento em que se retira o material da prateleira, ou quando o documento é emprestado, ou lido, ou quando influencia o leitor ou serve para alguma citação. O acesso remoto à biblioteca, o papel da Biblioteconomia para a concepção de uso e o próprio comportamento do usuário também foram postos em relevo por Fleming-May (2008, p. 52-53) em suas elucubrações iniciais.

Foi justamente a identificação dessa ampla gama de significados e a pouca clareza do conceito uso que levou Fleming-May (2008, p. 4) a se debruçar sobre o tema. A autora objetivou traçar dimensões e atributos do conceito para prover de um quadro teórico que auxiliasse 0 entendimento do uso da informação no âmbito das bibliotecas.

A noção a priori de sistema de informação e da multidimensionalidade do conceito uso foram o pano de fundo para que a autora pudesse discorrer sobre três categorias de estudo identificadas na literatura: teórico (theoretical), avaliativo (evaluation) e centrado no usuário (user-centric).

O estudo teórico é aquele que prioriza aspectos gerais, filosóficos e discussões teóricas sobre o uso; o estudo avaliativo está voltado à mensuração da ação de uso associado com um tipo particular de fonte ( $p$. ex., periódicos), serviços (p. ex., referência) ou de toda a biblioteca para fins de avaliação; já o estudo centrado no usuário leva em consideração o impacto do uso na vida do usuário.

Entretanto, Fleming-May (2008, p. 55) alerta que o conceito uso, quando pensado nas categorias acima, aparece conectado na condição de um conceito secundário, podendo assumir diferentes formas (em significados tácitos e explícitos) e podendo ser apresentado em múltiplos contextos num mesmo texto. A partir dessa constatação, a autora buscou traçar dois caminhos complementares:

1) consideração das três categorias e discussão individual dos tipos de uso abordados em diferentes pesquisas, com tipificações em distintos aspectos; e

2) proposição e apresentação de dimensões e tipologias com vistas a identificar padrões para auxiliar no entendimento do conceito uso. 
Para a discussão que se pretende - qual seja: identificar pressupostos de usuário e uso de informação influentes na CI - enfocarse-ão, aqui, apenas aspectos relacionados ao primeiro caminho. Neste, a autora trouxe algumas perspectivas identificadas nas investigações sobre estudos de usuários de produtos e serviços de informação, relacionadas no campo biblioteconômico, e sobre uso, identificado no contexto da CI.

Nos estudos de uso na CI, destacam-se aqueles sobre comportamento de uso de cientistas/tecnologistas desenvolvidos após a Segunda Guerra Mundial - conforme observado nas revisões da ARIST de Herner e Herner (1967), Paisley (1968), Allen (1969), Lipetz (1970), Crane (1971), Lin e Garvey (1972) - e acerca do comportamento de busca da informação (associado, ou não, à biblioteca), desenvolvidos no final de 1970 e início de 1980 - conforme apreciado nas revisões de Martyn (1974), Crawford (1978), Dervin e Nilan (1986) e Hewins (1990).

De acordo com Fleming-May (2008, p.56), as investigações em CI sobre comportamento podem ser identificadas ainda hoje nos estudos sobre uso, os quais buscam unir o comportamento ao conhecimento observado, visando o aperfeiçoamento de sistemas de informação.

Embora a efetiva ampliação do escopo daquele que seria o públicoalvo tenha ocorrido somente a partir da década de 1980, conforme foi possível observar na revisão de literatura de Dervin e Nilan (1986), o início da década de 1960 foi marcado por estudos sobre os fenômenos informação e necessidade, além de tematizar a previsão, as instâncias e a aferição do uso da informação, bem como o controle/melhoria do sistema, conforme observado nas revisões de Menzel (1966), Herner e Herner (1967), Paisley (1968), Allen (1969), Lipetz (1970), Crane (1971), Lin e Garvey (1972), Martyn (1974) e Crawford (1978)

De acordo com Fleming-May (2008, p. 56), embora os estudos de usuários muito frequentemente tragam uma perspectiva cognitiva e afetiva para o exame do comportamento informacional, uma tendência perceptível na área refere-se à posição teórica de que o comportamento de busca e uso da informação é estático, transacional, externo, ordenado e passível de mensuração.

Essa concepção mais estática, orientada ao sistema, passou a dividir espaço com outra orientação supostamente mais dinâmica, inclinada ao usuário. Nas publicações da ARIST aqui estudadas, a primeira revisão de literatura a identificar pesquisas considerando o aspecto subjetivo do usuário foi a de Martyn (1974), sendo esta seguida pelas revisões de Dervin e Nilan (1986) e de Hewins (1990).

A inclinação ao usuário de produtos e serviços de informação foi problematizada por Saracevic (2006). Para esse autor, não basta consultar o usuário para que este diga ao profissional de informação o que fazer para melhorar os recursos e serviços de informação e o próprio sistema. Para fazê-lo, existem importantes variáveis como o tempo gasto para consultar os usuários, o custo, o esforço institucional, dentre outras.

Outros fatores, segundo Fleming-May (2008, p. 58), se somam à problemática levantada por Saracevic (2006), quais sejam os problemas 
conceituais que incidem sobre o termo uso e os problemas metodológicos relativos à validade e à confiabilidade de métodos e de resultados obtidos.

A priorização da realização de estudos empíricos e quantitativos para a investigação das atividades relacionadas à necessidade e ao uso da informação, de acordo com Fleming-May (2008, p. 58), tem corroborado para o referido problema conceitual.

O caminho proposto por Fleming-May (2008, p. 59) prioriza o exercício da tipificação do conceito uso conforme padrões identificáveis nas formulações conceituais observadas na literatura. Tal caminho considerou os esforços teóricos que buscaram responder:

a)o que é uso, dimensão teórica;

b)o quanto se usa, dimensão avaliativa; e

c)quem usa, dimensão centrada no usuário, que considera o impacto do uso no cotidiano do usuário da biblioteca.

Quanto à dimensão teórica, o que é uso remete, segundo FlemingMay (2008), a uma questão que pouco tem sido enfrentada desde a década de 1970 e que, quiçá, por esse motivo, tem levado ao ainda presente obscurecimento do conceito uso. Em relação aos autores que se detiveram à questão, apenas dois foram destacados por Fleming-May (2008, p. 60-63): Maurice Line, autor do texto Draft definitions: information and library needs, wants, demands and uses, de 1974, e Norman Roberts, que teceu, no ano seguinte, um comentário sobre o referido texto. Sobre ambos os estudos, Fleming-May (2008, p. 63) comenta que infelizmente eles não tiveram impacto no sentido de encorajar o desdobramento de outras investigações sobre o conceito uso.

Em relação à dimensão avaliativa, o quanto se usa tem sido abordado tomando como instrumento de avaliação algum tipo de mensuração, focando a busca por qualidade, p. ex., do uso de uma coleção, de uma fonte de informação, de um serviço ou de uma instalação física. Com base no estudo de Weiss (1998, p. 4), Fleming-May (2008, p. 63112) explica que a avaliação pode apresentar duas variedades:

avaliação sistemática - consideram-se operações ou resultados de um programa ou política de informação, cotejando-os mediante análises quantitativas e/ou estatísticas com um conjunto de padrões explícitos ou a) implícitos identificados, ou com a avaliação quantitativa de casos de uso (número de logons em bases de dados, circulação de material, etc.); e

b)avaliação com foco na experiência do usuário - considera-se a experiência do usuário da informação em sua relação com as fontes disponíveis, bem como com a resposta efetiva ou potencial do sistema ou do serviço em relação à necessidade do usuário motivado a buscar a fonte de informação. 
A pesquisa centrada na avaliação quantitativa, ou seja, centrada na circulação, deu lugar, a partir da década de 1970, a estudos centrados nos usuários que passaram também a se interessar sobre quem usa, o que é usado e o que poderia ser usado ou como o serviço poderia ser aperfeiçoado. Partiu-se, para tanto, da premissa de que o uso da biblioteca e da informação decorre de uma necessidade individual dos usuários (FLEMING-MAY, 2008, p. 113).

Tal mudança para o foco nos usuários se deu diante da inconsistência obtida com o enfoque na avaliação. Essa premissa, exposta por Fleming-May (2008, p.112), foi embasada no estudo de Dervin (1977) que criticou a ênfase positivista dos estudos centrados em estatísticas que buscavam ensaiar previsões. Segundo esses autores, a ênfase na avaliação refletiu em confusões sobre a natureza dos estudos de uso.

Os estudos centrados nos usuários foram desenvolvidos, segundo Fleming-May (2008, p. 114), em três vertentes: 1. estudos de usuários (user studies), com foco no comportamento e nas necessidades dos usuários, trazendo discussões teóricas sobre a natureza de uso e as motivações diversas do usuário; 2 . estudos do uso (use studies), com foco na fonte de informação orientada para o uso; e 3 . estudos empíricos (empirical studies), com pouca preocupação sobre a evolução do conceito uso.

Embora Fleming-May (2008) tivesse constatado que as investigações centradas nos usuários foram desenvolvidas, em um primeiro momento, com enfoque em estudos de uso da informação de grupos específicos (studying the use of specific user groups) - conforme identificado, p. ex., na revisão de Crawford (1978) -, a autora reconhece que estas pesquisas encontraram sua "identidade" nas abordagens do uso da informação considerando a vida do usuário (approaches to use in the life of the user). Nesse caso, o usuário é concebido como um indivíduo dotado de cognição. Essa acepção pode ser observada nas "abordagens alternativas" ou "cognitivas" que consideram, complementarmente, a dimensão da vida cotidiana dos usuários, conforme identificado no estudo de Dervin e Nilan (1986) e considerado, em grande medida, pelas revisões da ARIST realizadas logo em seguida.

Ainda que a delimitação proposta por Fleming-May (2008) tenha servido de horizonte norteador para a identificação de pressupostos teóricos sobre usuário e uso na literatura da $\mathrm{CI}$, o paralelo que se buscou fazer aos aspectos teóricos debatidos nas revisões de literatura na ARIST demonstrou que com o recorte teórico de Flaming-May (2008) não foi possível explorar o universo dos 15 textos da ARIST analisados. Isso porque a própria natureza do referido recorte, que se limitou à consideração, a priori, de sistema de informação, não trouxe elementos de modo a dialogar com as análises expostas nos textos da ARIST de Pettigrew, Fidel e Bruce (2001), Case (2006), Courtright (2007) e Fisher e Julien (2009) que sucederam e ampliaram questões observadas nas revisões de Dervin e Nilan (1986) e de Hewins (1990). 
As revisões da ARIST de 2001, 2006, 2007 e 2009 além de considerarem a noção de sistema, a dimensão objetiva da informação, a dimensão subjetiva do usuário e o início do estudo de aspectos da vida cotidiana relativas ao uso, também contemplaram estudos sobre a dimensão social da informação. Nessa dimensão, o contexto comunicativo é considerado e os sujeitos que se relacionam e interagem entre si não seriam apenas usuários de sistemas, mas, sim, sujeitos que usam, se apropriam e produzem informação e conhecimento.

\section{Usuário e uso de informação no âmbito interativo e contextual}

Uma terceira fase identificada nas revisões de literatura da ARIST refere-se à reflexão sobre usuário e uso de informação inscrita nas novas formas de construção de informação e conhecimento, que são operacionalizados, sobretudo, com a expansão da capilaridade e dos meios de acesso à Internet.

As noções de usuário e uso da informação, nessa direção, podem ser ampliadas ao se considerar outras possibilidades de criação de objetos de estudo. $O$ sujeito em questão passaria a se referir não apenas àquele indivíduo que gerencia ou que faz uso da informação num sistema, mas também àquele que produz informações e conhecimentos, os apropriam e os disseminam em distintos contextos e em diferentes formas de interação e de intervenção.

As noções estritas de usuário do e no sistema de informação, dessa forma, deixariam de conotar, tão-somente, um sujeito-container de informação (um "autômato" do sistema) ou um sujeito singular e cognitivo. Abrir-se-ia margem, então, para a concepção de um sujeito agente apreendido em relação social e em contexto, ou seja, um ator cognitivo-social.

Parte dessa ampliação conceitual tem sido corroborada pelas possibilidades hodiernas de difusão, de acesso e de uso de informação propiciadas com as transformações tecnológicas, com a criação de variados tipos de hardware e software e, sobretudo, com o advento da World Wide Web ou WWW ou, simplesmente, Web.

A Web tem se apresentado como um espaço inovador que congrega diferentes formas de inter-relação de conteúdos, de fluxos de informação, em canais ou fontes de informações diversos e justapostos mediante a interconectividade hipertextual ${ }^{9}$.

Diante de tais características, a Web tem emergido, para instituições intermediadoras de informação públicas e privadas, de pequeno e médio porte, como um lugar em que as pretensões de domínio completo de quem ou sobre quem acessa a informação são minimizadas, bem como as

\footnotetext{
9 O hipertexto é um texto em formato digital que pode congregar informações diversas - blocos de textos, palavras, imagens ou sons - acessadas referencialmente, por demanda, mediante interconexão de hyperlinks ou links. Os conteúdos ligados a outros textos, via links, estendem ou complementam o hipertexto principal. A Web é o sistema mais conhecido onde se operacionalizam interconexões hipertextuais.
} 
pretensões de antecipação e de previsão, pressupostas em muitos estudos de comportamento informacional, são objeto de questionamento.

A multidimensionalidade e a virtualidade da Web constituem um canal difuso, no qual a ideia de controle sobre aquele que usa o sistema tem o sentido, em grande medida, esvaziado diante da dificuldade de se definir um público-alvo. A aparente emergência de um distinto modelo sociotécnico admite, assim, a existência de uma "audiência não planejada", de difícil controle. ${ }^{10}$

Logo, frente a esta nova infraestrutura informacional, ao deslocar a atenção estrita à noção de usuário e de uso da informação num sistema e ao considerar, ademais, o sujeito que transcende sua ação ao produzir e se apropriar de informação e conhecimento, os aspectos comunicativos, interativos e contextuais passam a assumir lugar de destaque na literatura da CI.

Trazendo luz a tais estudos, as revisões da ARIST da última década têm apontado para a existência de um enfoque teórico vinculado às investigações sobre comportamento informacional, trazendo modelos mais amplos àqueles vinculados estritamente ao sistema, deixando de limitar o horizonte interpretativo aos conceitos de informação em seu aspecto objetivo e/ou subjetivo.

Na revisão de Pettigrew, Fidel e Bruce (2001), assim como já observado em Dervin e Nilan (1986), a concepção de usuário transcende o contexto da informação em C\&T. Entretanto, a ação interpretativa do sujeito que usa a informação e produz conhecimento deixa de estar situada no âmbito cognitivo isolado. As ações passam a serem consideradas no âmbito da interação e da intervenção entre sujeitos num determinado contexto.

À luz do enfoque social identificado por Pettigrew, Fidel e Bruce (2001), a revisão seguinte de Case (2006) fundamentou-se na identificação do amplo quadro de estudos de natureza aplicada. Tais estudos foram classificados por Case (2006) como usuários buscadores de informação por ocupação (cientistas, engenheiros, pesquisadores, gestores etc.), por função (público geral, pacientes, estudantes etc.) e por grupo demográfico e social (crianças e adolescentes, imigrantes, pessoas pobres, mulheres sem-teto e idosos).

A pesquisa de Courtright (2007), a exemplo da investigação de Case (2006), continuou considerando a noção de usuário de informação de forma ampla. O conceito foi abordado em estudos de natureza qualitativa e tomando por base as formas compartilhadas de interação e de

10 A exceção à ideia de "audiência não planejada" da Web tem ocorrido, p. ex., no caso de interesses econômicos de grandes corporações e/ou no caso de interesses políticos de países centrais do capitalismo. À luz de tais determinações, fatos recentes têm evidenciado a real possibilidade de antecipações ou registros globais do uso de informações que circulam na Web. No ano de 2013, o administrador de sistemas e ex-analista da Agência de Segurança Nacional (NSA, em inglês) dos Estados Unidos - Edward Joseph Snowden - revelou ao mundo, mediante os jornais The Guardian e The Washington Post, a espionagem realizada por aquela agência em comunicações e tráfego de informações em rede de diversos países, sobretudo europeus e latino-americanos, por intermédio de diferentes softwares e formas de escutas e interceptações. Os países espionados, inclusive o Brasil, investigam a colaboração de grandes empresas - como Google, Yahoo!, Facebook, Microsoft, Skype, You Tube, AOL e Apple, dentre outras - que possivelmente teriam colaborado com o fornecimento de informações de seus usuários à NSA. 
intervenção social entre sujeitos. Nessa revisão, as relações sociais dos sujeitos que usam, produzem e se apropriam de informação e de conhecimento passaram a ser referenciadas a partir da noção central de contexto.

A até então última revisão da $A R I S T$, sob a responsabilidade de Fisher e Julien (2009), reafirma a tendência identificada nos textos anteriores de Pettigrew, Fidel e Bruce (2001), de Case (2006) e de Courtright (2007), em cujo aspecto amplo da noção de usuário não se atém somente ao contexto da informação em C\&T e em cuja variabilidade da agência do sujeito se inscreve na noção de contexto e nela obtém evidências das novas formas de produção de informação e de conhecimento identificadas num modelo sociotécnico que aparentemente vem emergindo.

O aspecto teórico destoante presente nas revisões da ARIST da década de 2000 refere-se à relativa atração identificada entre as dimensões subjetiva e social de informação. Nessa direção, os autores captaram o caráter complementar entre a noção de sujeito produtor de sentido com a ação e a prática de informação dos sujeitos, ou seja, com a capacidade destes de se relacionarem e de interagirem comunicativamente entre si e em contextos sociais diversos para a produção e apropriação de informação e conhecimento. É perceptível que a acepção de contexto nestes estudos passa a ter posição privilegiada

\section{Considerações finais}

O recorte teórico proposto por Fleming-May (2008) foi ilustrativo para a visualização da primeira e da segunda fase dos estudos sobre usuário e uso da informação nas revisões da ARIST. Em tal delimitação, a autora tomou como exemplo o contexto institucional da biblioteca e como parâmetro os enfoques teóricos que envolvem o pressuposto do sistema de informação. Tais enfoques trouxeram elementos esclarecedores sobre o uso da informação em relação às práticas profissionais dedicadas a serviços e a gestão e/ou elaboração de produtos informacionais.

O quadro categórico de Fleming-May (2008) tocante ao conceito uso - dimensões teórica, avaliativa e centrada no usuário - foi elucidativo para subsidiar a apreensão do ordenamento do trabalho empírico em sistemas de informação - focado, mormente, nas tomadas de decisões quanto ao serviço de aquisição de fontes de informação, à priorização e gestão de recursos e à avaliação de serviços, de pessoas e de instalações - além de auxiliar trazendo problematizações teóricas sobre o uso da informação nesses sistemas.

Além dessa dimensão estrita de sistema, foi possível observar que, a partir da década de 2000, as revisões da ARIST catalisaram estudos cujo conceito de usuário passou a contemplar, em um só tempo, o sujeito que usa, produz e se apropria de informação e de conhecimento.

Essas revisões evidenciaram, ademais, o início da transcendência das preocupações restritas ao processo cognitivo do sujeito. Infere-se que o sujeito, ao deixar de ser tomado apenas como singularidade cognitiva, 
passou a ser concebido como um agente que traz consigo institucionalidades, posicionamentos e visões de mundo inseridas e compartilhadas coletivamente, em inscrições cognitivas de sua herança cultural, social e política.

É possível dizer ainda que a transcendência da noção estrita de sistema e do enfoque no processo cognitivo do usuário tem aberto margem para a ampliação de objetos de estudo na CI com vistas à compreensão da construção e da apropriação de informação e de conhecimento em sociedades ou em grupos específicos, ou seja, em redes sociais, algo que já era preconizado nas revisões da ARIST das décadas de 1960 e início de 1970 (HERNER; HERNER, 1967; PAISLEY, 1968; ALLEN, 1969; LIPETZ, 1970; CRANE, 1971; LIN; GARVEY, 1972). Conforme observado naquelas revisões, parte dos estudos mapeados utilizavam como procedimento analítico os processos de comunicação formal e informal de cientistas e tecnólogos visando à obtenção de informação sobre comportamento de busca, recuperação e uso de informação em sociedades científicas específicas, isto é, em escolas invisíveis.

Hodiernamente, a releitura de tal concepção na CI é corroborada, em grande medida, pelas novas formas de ação, intervenção e interação em rede, ou seja, em novos contextos tecnológicos de comunicação. Essas infraestruturas informacionais têm influenciado os modos de construção e apropriação individual e coletiva do conhecimento, criando composições distintas de transmissão de pretensões comunicativas, bem como possibilitado a validação de informações e a troca de experiências intersubjetivas em meios que trazem novas formas de experimentação da relação espaço-tempo.

O usuário, nesse novo cenário, deixa de ser concebido estritamente como um sujeito passivo, um reservatório (container) de informação, bem como deixa de ser interpretado somente como um objeto para o escrutínio de práticas e comportamentos por intermédio do estudo de processos cognitivos particulares. Entra em cena, portanto, a noção unívoca de usuário-produtor de conhecimento.

O conceito de uso de informação, como objeto de estudo, passa a compartilhar importância quando em comparação com outros conceitos. Dependendo do fenômeno a ser estudado - p. ex., no âmbito de uma rede social - aspectos como contexto, interação, agência do sujeito, produção de sentido, produção de conhecimento, apropriação de conhecimento, dentre outros, somam-se ou complementam a noção de uso.

Enfim, a conotação causa-efeito proveniente da noção estática de sistema e ancorada no processo de circulação da informação - leia-se: informação inserida e organizada num sistema, logo, pronta para ser buscada, recuperada e usada - ou da noção mais dinâmica decorrente da concepção de usuário do e no sistema - leia-se: usuário produtor de sentido e fonte para o desenho ou o redesenho do sistema - tem aberto caminho para a investigação complementar dos processos e dos fenômenos informacionais envolventes na relação e na interação entre os usuários que produzem conhecimento, bem como nas formas de intervenção socioinformacional desses sujeitos. Nesse caso, juntamente à 
noção de contexto, o entendimento amplo de sujeito na CI parece que vem ocupando (ou mereceria ocupar) posição central no âmbito das agências informacionais, algo que revela a necessidade da realização de estudos pormenorizados sobre o assunto.

\section{Referências}

ALLEN, T. J. Information need and use studies. ARIST, v. 4, p. 3-29, 1969.

ARIST - THE ANNUAL REVIEW OF INFORMATION SCIENCE AND TECHNOLOGY. Silver Spring: ASIS\&T, [1966 - ]. Disponível em: $<$ http://www.asis.org/Publications/ARIST/statement.php >. Acesso em: 28 nov. 2012.

CASE, D. O. Information behavior. ARIST, v. 40, p. 293-327, 2006.

COOL, C. The concept of situation in information science. ARIST, v. 35, p. 5-42, 2001.

COURTRIGHT, C. Context in information behavior research. ARIST, v. 41, p. 273-306, 2007.

CRANE, D. Information needs and uses. ARIST, v. 6, p. 3-39, 1971.

CRAWFORD, S. Information needs and uses. ARIST, v. 13, p. 61-81, 1978.

DERVIN, B. Useful theory for librarianship: communication, not information.

Drexel Library Quarterly, v. 13, n. 3, p. 16-32, 1977.

DERVIN, B.; NILAN, M. Information needs and uses. ARIST, v. 21, p. 333, 1986.

FISHER, K.; JULIEN, H. Information behavior. ARIST, v. 43, p.317-358, 2009.

FLEMING-MAY, R. A. "Use" in the literature of Library and Information Science: a concept analysis and typology. 2008. 204f. Dissertation (Doctor of Philosophy in the Department of Communication \& Information Sciences) - The University of Alabama, 2008.

FORD, N. Criativity and convergence in information science research: the roles of objectivity and subjectivity, constraint, and control. JASIS\&T, $\mathrm{v}$. 55, p. 1169-1182, 2004.

GASQUE, K. C. G. D.; COSTA, S. M. S. Evolução teórico-metodológica dos estudos de comportamento informacional de usuários. Ci. Inf., v. 39, n. 1, p. 21-32, jan./abr. 2010.

HERNER, S.; HERNER, M. Information need and use studies in science and technology. ARIST, v. 2, p. 1-34, 1967.

HEWINS, E. T. Information need and use studies. ARIST, v. 25, p. 145$172,1990$. 
HJØRLAND, B. Arguments for philosophical realism in library and information science. Library Trends, v. 52, p. 488-506, 2004.

JÄRVELIN, K.; WILSON, T. D. On conceptual models for information seeking and retrieval research. Information Research, v. 9, 2003. Disponível em: <http://www.informationr.net/ir/9-1/paper163.html>. Acesso em: out. 2012.

JOHNSON, J. D. On contexts of information seeking. Information Processing \& management, v. 39, p. 735-760, 2003.

LIN, N.; GARVEY, W. D. Information need and use studies. ARIST, v. 7, p. 5-37, 1972.

LINE, M. B. Draft definitions: Information and library needs, wants, demands and uses. AsLib Proceedings, v. 26, n. 2, p. 87-87, 1974.

LIPETZ, B.-A. Information needs and use. ARIST, v. 5, p. 3-32, 1970.

MARTYN, J. Information need and use studies. ARIST, v. 9, p. 3-23, 1974.

MENZEL, $H$. Information needs and uses in science and techonology. ARIST, v. 1, p. 41-46, 1966.

PAISLEY, W. Information needs and uses. ARIST, v. 3, p. 1-30, 1968.

PETTIGREW, K. E. Waiting for chiropody: context results from an ethnographic study of the information behavior among attendees at community clinics. Processing \& Management, v. 35, p. 801-817, 1999.

PETTIGREW, K. E.; FIDEL, R.; BRUCE, H. Conceptual frameworks in information behavior. ARIST, v. 35, p. 43-78, 2001.

ROBERTS, N. Draft Definitions: information and library needs, wants, demands and uses: a comment. Aslib Proceedings, v. 27, n. 7, p. 308313, 1975.

SARACEVIC, T. Relevance: a review of the literature and a framework for thinking on the notion in information science. Part II. Advances in Librarianship, v. 30, p. 3-71, 2006.

SREFT-MABRY, J. A social judgment analysis of information source preference profiles: an exploratory study to empirically represent media selection patterns. JASIS\&T, v. 54, p. 879-904, 2003.

THOMAS, N. P.; NYCE, J. M. Context as category: opportunities for ethnographic analysis in library and information science research. New Review of Information Behavior Research, v. 2, p. 105-118, 2001.

WILSON, T. D. Human information behavior. Informing Science Research, v. 3, n .2, p. $49-55,2000$. 